\title{
USE OF BIOENGINEERING TECHNIQUES TO PREVENT LANDSLIDES IN NEPAL FOR HYDROPOWER DEVELOPMENT
}

\author{
ROSHANA RAUT \& OVE TOBIAS GUDMESTAD \\ University of Stavanger, Norway.
}

\begin{abstract}
Bioengineering techniques are useful approaches to prevent landslides as they improve slope stability and maintain ecological balance. They are mostly suitable to be deployed in developing countries because of their cost effectiveness and environmentally friendly nature. This article discusses the landslide problems that many hydropower sites in Nepal face every year and the possibility of using various bioengineering techniques to cope with such problems. Despite a long history of bioengineering practices in Nepal, they have not been used properly in the hydropower sector. Mini-/ micro-hydropower plants are very common in Nepal and are specially constructed in sloping terrains for fulfiling the needs of electricity transmission to rural areas where landslides occurrence is very frequent. The application of suitable bioengineering techniques before/during the construction of hydropower plants can reduce the risks associated with landslides and help in increasing the lifetime of the plants. However, a successful bioengineering technique in those areas requires more scientific research and a good understanding of the factors that influence its effectiveness. Different aspects affecting bioengineering techniques are also presented in this article. The implementation of bioengineering techniques in this renewable energy sector will contribute to the sustainable development of the local community.

Keywords: bioengineering techniques, development, hydropower, landslides, Nepal.
\end{abstract}

\section{INTRODUCTION}

Hydropower is a major source of energy in Nepal. The distinct topography and sloping hills of Nepal provide tremendous opportunities for the development of hydropower plants [1]. However, the hilly areas are prone to landslides because of their weak and weathered geographical structures with many tectonic uplifts and erosion of slopes. The prolonged period of precipitation and snowmelt, in addition to anthropogenic activities such as deforestation, irrigation, mining, road construction, etc. make such areas even more prone to landslides. Due to these reasons, Nepal faces hundreds of landslides every year. Two underlying factors usually trigger landslides in Nepal [2-4]. They are: (a) rainfall and (b) earthquakes. The monsoon is the main period of rainfall in Nepal, which lasts from June to August, causing precipitation of approximately $80 \%$ of the annual rainfall. The mean annual rainfall ranging between 1,500 $\mathrm{mm}$ and 2,500 $\mathrm{mm}$ prevails over most parts of Nepal [5]. The distribution of precipitation is uneven during the monsoons, and areas with heavy rainfall are more likely to suffer from landslides during this period.

Soil bioengineering techniques are relevant for mitigating the risks of landslides in Nepal. Bioengineering techniques are applied vegetation-based techniques that use engineering practices integrated with ecological principles $[3,6,7]$. The fundamental principle of these techniques is that it takes the benefits of the biological and technical characteristics specific to natural vegetation, or in a combined form with living or non-living structures. Consequently, it helps in the enhancement of the ecological balance and the 
maintenance of slope stability. It is a cost-effective technique and utilizes only locally available materials. Despite the involvement of engineering practices, the labour cost for bioengineering is low, which makes it efficient and mostly useful for developing countries like Nepal $[3,6,8]$.

Soil bioengineering methods currently used for preventing landslides have been introduced in Nepal more than 30 years ago [8]. Thus, it is not a totally new topic to be considered. The common practices in Nepal against landslides include brush layering, palisades, vegetative stone pitching, live check dams, and fascines. Dhital [7] describes these methods in detail. Vegetation is used in soil bioengineering to reinforce and stabilize the slopes. They carry a high function of sustaining biodiversity and having a very positive influence on the ground structure, and thereby on the whole ecosystem. They create a balance between soil and water. The use of vegetation combined with several engineering structures for bioengineering performs both the basic and engineering functions to maintain slope stability.

Landslides destroy hundreds of hydropower plants each year in Nepal. The proper utilization of bioengineering techniques in the hydropower sector can prevent landslides or minimize the extent of the damages they cause. In addition, these techniques also help the ecological and sustainable development of the local community, and contribute to making the livelihood of rural people better.

\section{PROBLEMS OF LANDSLIDES IN HYDROPOWER DEVELOPMENT}

Due to the difficult terrain, the development of hydropower is a rather challenging task in Nepal. In addition, the population, being scattered in smaller communities, is also a problem for the transmission of electricity in rural areas. Because of these reasons, mini- and microhydropower plants are more popular. However, they face huge problems of landslides during the construction and operation periods.

\subsection{Problems in avoiding landslides}

The various phases of a hydropower project include planning, designing, construction, operation, and maintenance. Steps for avoiding landslides should be taken from the inception stage of planning. Risk zones are evaluated through survey and from geological studies. Nevertheless, the means to protect against and prevent landslides are most often not integrated. The major reasons for not including measures for avoidance of landslides are listed below:

- Lack of specific guidelines for the protection of hydropower plants.

- Lack of funds to implement preventive measures for landslides.

\section{2 problems in hydropower system after landslides}

Landslides induced by the earthquake in 2015 damaged a large number of hydropower installations [9]. Out of the total installed capacity of $787 \mathrm{MW}$ of hydropower facilities, a combined capacity of $115 \mathrm{MW}$ was severely damaged, while $60 \mathrm{MW}$ was partially damaged. In addition to this, landslides also impaired hydropower projects that were under construction. The major impact of landslides on hydropower plants is the destruction of transmission lines/ poles or other parts of the plants such as penstock, headwork, anchor blocks, powerhouse, etc. It takes much time and cost for repairing/replacing the damaged parts inducing the large 


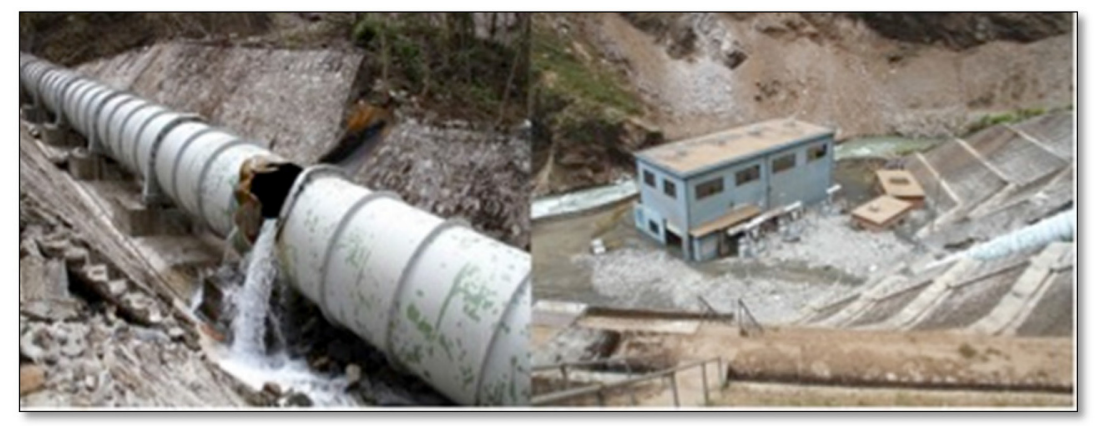

Figure 1: Damaged penstock pipe of Bhote Koshi hydropower plant (left) and Powerhouse submerged in soil and access roads blocked by landslides (right) (Source: Rai, 2015).

downtime of the plant. Consequently, it also causes hardship on the daily life of people who depend on that power plant.

Figure 1 The left part of the figure shows the burst penstock pipe of the Bhote Koshi hydropower plant. It is severely damaged by the rock falls during the landslides induced by the Nepal earthquake of 2015. The right part shows the submerged powerhouse of the same hydropower plant and the access road to the powerhouse being blocked by landslides. Rai [10] explains about halting of operation of several mini/micro-hydropower plants due to the blockage of access roads by landslides.

\section{UNDERSTANDING THE ROLE OF VEGETATION ON INCREASING SLOPE STABILITY}

Vegetation is the fundamental part of the soil bioengineering technique. It plays a vital role in increasing slope stability. Understanding the roles of vegetation helps in proper implementation of the procedures and in the selection of site-suitable plants and methods. The soil stability is driven by two major properties of plants. They are: (a) mechanical and (b) hydrological $[7,11]$. Increasing the shear strength of the soil is a function of plant roots, which is endorsed as a mechanical property [7]. The roots form a network-like structure underneath the ground that binds and anchors the soil. Consequently, it increases the shear strength. Steinacher et al. [12] explains this property of roots in three ways: (i) anchoring (ii) lateral support by crossing zones of weakness, and (iii) acting as large fibrous binders within a weak soil mass. Similarly, the hydrological property includes various processes such as interception, precipitation, evaporation, storage, leaf drip, pool formation, water uptake, transpiration, and infiltration. Hydrological effects involve removal of soil water by evapotranspiration through vegetation $[11,13]$. It increases ground suction or reduces pore water pressure, which ultimately increases the shear strength of the soil. Furthermore, evaporation reduces not only the moisture content but also the weight of the soil mass. Overall, these properties of plant roots significantly contribute to maintaining slope stability.

Figure 2 shows an illustration of a tree with shrubs and grasses on the ground surface. Roots of ground covers such as shrubs and grasses hold the soil and protect the surface soil from being washed away by heavy rainfall. They also help to maintain the absorptive capacity of soil, slowdown the velocity of runoff and also act as a filter to catch sediments. Vegetation like trees balances the processes of absorption and evapotranspiration. Tree roots stabilize the slopes by tying the soil layers together. However, for this particular function of 


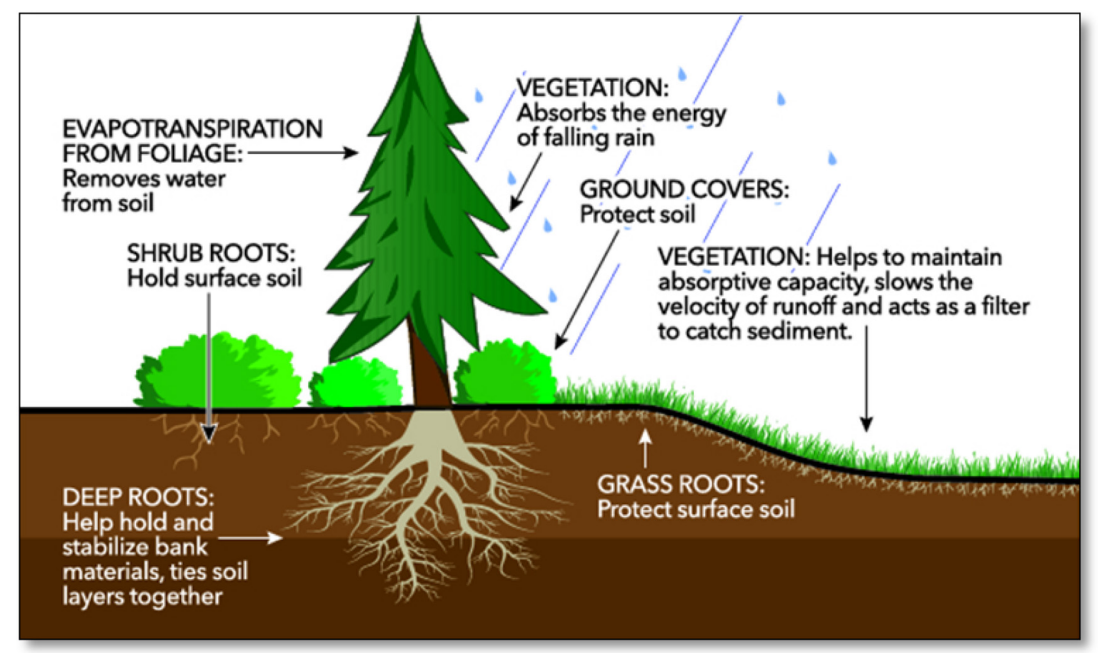

Figure 2: Diagrammatic representation of vegetation with its various functions (Source: Stewards, 2017).

slope stabilization, trees with deep root systems should be chosen. Such roots penetrate deep into the soil and make the bioengineering techniques stronger and more effective.

\section{HYDROPOWER DEVELOPMENT AND BIOENGINEERING}

Several discussions on the status of hydropower and their development are consistently made in Nepal. 'Guidelines for the Study of Hydropower Projects' that is provided by the Department of Electricity Development (DoED) Nepal is adopted as the national guidelines for the study of hydropower projects. It aims to maintain consistency in hydropower projects by simplifying construction procedures. It also helps to establish standard criterion for the different phases of hydropower projects [14].

The planning of a hydropower project comprises three major phases of study:

1. Reconnaissance or Preliminary Study

2. Pre-feasibility Study

3. Feasibility Study

Guidelines for hydropower development vary a little depending upon the capacities (micro/ small/large) and the type of scheme (Run-of-river type or Storage type). However, they follow similar processes of development. The feasibility study involves a detailed and comprehensive study and survey of the topographical, geological, hydrological, and environmental features of the proposed project site. It is a long process ranging from carrying out a feasibility study to the completion of the whole project. During the environmental studies at the project site, information about all specific environmental issues is collected. An assessment of their possible impacts is also carried out, and the mitigation measures are developed. However, guidelines for hydropower development completely lack strategies about the implementation of preventive measures against probable landslides that could occur in the future. 
According to Howell [3, 6], application of bioengineering depends on two basic factors at the existing site. Those two factors are as follows:

1. A site/slope that requires a combination of various forms of techniques to obtain an optimum effect:

- Wire bolster cylinders and grass slip planting

- Grass seeding, mulching, and wide mesh jute netting

- Standard mesh jute netting and grass slip planting

2. A site comprising several slope sections, each of which requires diverse techniques:

- For a steep slope - Standard mesh jute netting and grass slip planting

- For a moderate slope - Contour grass lines

- For a gentle slope - Toe requiring bamboo planting

In the case of a hydropower development project, the criticality of its structures should also be considered. Suitable bioengineering techniques can be adopted conferring to the available physical and geographical conditions. These techniques can be applied at the sideways slopes of the primary structure of a hydropower plant. It will consequently provide time for the growth of the plants and make the structure of bioengineering stronger until the completion of the project. However, such techniques should be avoided in areas that are closer to construction, where there are chances of damages to the planting. Building materials, manpower, and so on can harm bioengineering techniques in those areas. Likewise, for construction reasons, several existing plants are also destroyed. For example, construction of anchor blocks and powerhouse, lying out of penstock pipes, etc. These locations require more attention and need to be vegetated later on. Table 1 includes some suggested methods of bioengineering applicable in the context of hydropower development.

Table 1: Applicable bioengineering techniques and their effects. Modified from: (Source: Dhital, 2013; Howell, 2001).

Suggested method

S.No. of Bioengineering Description

What kind of effects is obtained?

1. Planted grass lines Rooted cuttings are planted (horizontal) in lines across the slope

Provides surface cover

Reduces runoff speed

Catches debris and protects the slope

2. Planted grass lines Rooted cuttings are planted (diagonal) in lines running diagonally across the slope

3. Grass seeding Grass seeds sown directly on the site

Effects similar to (1)

Drainage of surface water

Shrubs and trees are planted

4. Shrub and tree planting at regular intervals on the slope

Easy vegetation of larger, rocky, and steep slopes

Reinforces and anchors the slope Increases slope stability as they

Woody cuttings are laid grow

5. Brush layering across the slope following Prevents the development of rills the contour Strong barrier to trap debris

Reinforces the slope

Provides drainage 
Table 1: (Continued)

Suggested method

S.No. of Bioengineering Description What kind of effects is obtained?

6. Palisades

Similar to brush layering, Effects similar to brush layering

7. Fascines/Contour wattling but the cuttings are planted

wattling

Bundle of live branches laid in shallow trenches being buried by soil
8. Vegetated stone pitching

A combination of dry stone walling where vegetation is planted in the gaps

9. Live check dams

Large woody cuttings planted across a gully following the contour
Provides a very strong form of armouring

Effects similar to brush layering

Specialized form of gravity

Catches debris
Armours and reinforces gully floor

10. Vegetated bamboo crib walls retaining structure using on-site fill material

Immediate protection

Provides long-term advantages of slope stabilization

The techniques mentioned above can be applied for slope stabilization based on existing site conditions and the presence of hydropower structures. A well-defined knowledge regarding the plants' role for increasing slope conditions is very crucial for the efficient use of such techniques.

\section{FACTORS AFFECTING THE EFFECTIVENESS OF BIOENGINEERING TECHNIQUES}

Despite soil bioengineering being used from a long time, plantation has not been carried out with explicit knowledge. Understanding the factors that influence the effectiveness of such techniques helps in the appropriate implementation of bioengineering [15].

\subsection{Geological features}

Nepal has a diverse land feature from south to north. Of these zones, Siwalik (Sub-Himalayan) and Lesser Himalayan zones are more susceptible to landslides. Slopes with a variation in altitude from 150 to $1500 \mathrm{~m}$ comprise immature sloping lands. They usually face the problems of deforestation and high amount of rainfall during the monsoon, which make them weak and prone to landslides [7]. Land topography also plays a significant role in deciding the appropriateness of any bioengineering technique. The growth of vegetation greatly depends on the altitude as well as the slope features such as slope facing (towards either south or north). In Nepal, southward facing slopes receive more sunshine than those facing northwards, and are usually dry. Howell [3, 6] discusses suitable bioengineering techniques concerning the slope angle and slope length.

\subsection{Soil and climatic conditions}

The growth of a plant depends on soil and climatic parameters. Roots are regarded as the primary contributors for increasing slope stability. However, the type of soil and the factors present in the soil influences their growth. A good soil structure usually comprises sufficient 
pores between its particles that allow water and air to enter quickly. It has a good drainage system as well as it holds adequate moisture and minerals required for the healthy and proper growth of a plant. Hence, depending upon the type of soil, plants with specific root systems should be selected. The soil holds biological, chemical, and hydrological properties that influence the growth of a plant [16]. Biological properties refer to the presence of microorganisms and humus content. The chemical factors are the $\mathrm{pH}$ of the soil, soil temperature, amount of nitrogen, and the availability of essential nutrients for plant growth. The hydrological factors include the moisture content in the soil. The appearance and depth of the root system depend on the type of soil. The suitability of bioengineering techniques is thus dependent on the nature of the soil and the essential nutrients it contains for plant growth. A soil test should be performed for its strength parameters such as cohesion, compression, shear, the angle of friction, etc.

Climate varies from tropical to arctic within $200 \mathrm{~km}$ from south to north in Nepal, and the temperature decreases with elevation and drops by $6.5^{\circ} \mathrm{C}$ per $1000 \mathrm{~m}$. Northern regions are quite wetter than the south. The mean temperature remains around $15^{\circ} \mathrm{C}$ and the country receives about 1500 to $2500 \mathrm{~mm}$ rainfall every year of which the monsoon contributes to about $80 \%$ of the total annual rainfall [7]. Landslides in Nepal are triggered mainly by rainfall. Therefore, it is suitable to carry out bioengineering works in the pre-monsoon season and during winter. It gives time for proper growth and development of root structures.

\subsection{Selection of the best technique}

By carrying out a detailed site investigation, survey, and study of the geological features of the site, one can select the best method of bioengineering. The best techniques are those that match the available site conditions, slope and altitude conditions, soil and climatic features, and perform their functions efficiently to stabilize the slopes. Slope features must also be observed. Howell $[3,6]$ mentions the danger of surface scour for an existing slope longer than $15 \mathrm{~m}$. In such a case, some physical scour check like wire bolsters can be used. Similarly, if the slope is made up of poorly drained material with relatively high clay content, problems of shallow slumping have to be addressed. In such a case, a bioengineering technique that also includes a proper drainage system must be selected. Some sites may require a combination of techniques. The design of any technique must be site-specific, relying on the nature of the slope, soil characteristics, climatic factors, and efficiency of that technique for preventing landslides. An initial assessment of landslide-prone slopes can help in choosing the appropriate method of soil bioengineering.

\subsection{Selection of plants}

Vegetation performs a crucial function of sustaining biodiversity and giving a positive influence on the ground structure by creating a balance between the soil and water. Plants perform both the basic and engineering functions, and maintain slope stability when combined with engineering structures for bioengineering. However, not all types of plants possess the characteristics suitable for bioengineering. Thus, the best plants should be selected for this purpose. Howell et al. [3, 6, 8] explain that selecting the best plants for bioengineering means selecting those plants that possess enough root strength, have high abundances, are more likely to be available in the local or surrounding areas, propagate quickly, and are adjustable and suitable to the climatic conditions of Nepal. A combination of Shorea robusta and grassland is common on the lower slopes of the Siwalik Hills [7]. 


\subsection{Economic aspects}

An economically feasible bioengineering technique is based on the cost of materials and human resources. It also includes the cost of transportation of materials and cost of construction. Detailed research on the potential plants can make this technique more economical as it prevents the loss of selecting useless plants. Subsequently, selection of local plants that possess characteristics suitable for bioengineering and the enhancement of community participation can also make it more economical. Economical aspects of bioengineering are also considered as the key to success for ecosystem re-establishment [7].

\subsection{Survival and growth rate of plants}

Plants are the foundation for bioengineering techniques. Life and longevity of such methods entirely depend upon the survival and growth rate of the plants. The efficiency of bioengineering also increases with plant survival. Harsh climatic conditions and heavy rainfall have a great impact on plant growth. In Nepal, there is high probability of premature plants being quickly washed away by the monsoon [8]. Hence, plants should be rooted in suitable environmental conditions, and they require routine investigations for their survival and growth.

\subsection{External intervention}

Longevity and effectiveness of bioengineering can be prolonged by protection and proper maintenance of the plants and structure after construction. Among the various damages to bioengineering, deforestation and forest fires are the primary ones in Nepal. In addition to this, people living in hilly regions raise cattle such as goats and sheep and leave them in the hills for grazing $[3,6]$. Ultimately, they harm bioengineering practices, as the animals feed on the plants and destroy newly cultivated plants and built structures. As a result, they alter the efficiency. Implementing strict rules and regulations for proper use of forests and their conservation, and establishing community forests can decrease such type of external interventions. The government plays a great role in implementing such rules and regulations. Public awareness is also essential since the communities themselves can contribute to forest conservation.

\subsection{Root-soil reinforcement}

It is very essential to understand the root-soil relationship for a successful implementation of bioengineering techniques. The soil exerts shear strength, which is a property of the cohesiveness and resistance of the soil to the shearing forces exerted by gravity, moving fluids, and mechanical loads. The soil is strong in compression but weak in tension, while it is just the opposite in the case of roots [17]. The combination of soil and roots form a matrix, which is significantly higher in reinforcement. Accordingly, it exceeds the resisting forces, making the slopes stable against landslides. A proper understanding of root-soil interaction leads to the choice of the best plants for bioengineering techniques. Best plants refer to having tap root systems with a high concentration of roots and proper root diameter that contribute highly to increasing the shear strength.

\section{CONCLUSIONS}

The longevity of hydropower plants, including mini- and micro-hydropower plants, is helpful in fulfiling the energy demand as well as for the sustainable development of a country like 
Nepal. The implementation of bioengineering techniques in hydropower sites improves the safety of the power plants from landslides and maintains the ecological balance of the region. A complete site investigation and knowledge of available hydrological, geographical, and topographical conditions is required for a successful employment of this technique. For the proposed hydropower sites, bioengineering techniques should be applied prior to the start of construction in order to provide enough time for the vegetation to grow and become strong. Consequently, it is also important to understand the factors contributing to the effectiveness of bioengineering techniques. The use of local plant species, local work force, and other local resources make this technique economic, practical, and effective.

\section{ACKNOWLEDGEMENTS}

This article is based on the master's thesis of the first author, reproduced with permission from the University of Stavanger (UiS). The first author would like to thank UiS and the International Research Institute in Stavanger (IRIS) for funding the thesis through a grant provided by the Research Network for Sustainable Energy.

\section{REFERENCES}

[1] Nepal, R., Roles and potentials of renewable energy in less-developed economies: The case of Nepal. Renewable and Sustainable Energy Reviews, 16(4), pp. 2200-2206, 2012.

https://doi.org/10.1016/j.rser.2012.01.047

[2] ADPC, Nepal Hazard Risk Assessment Part 1: Hazard Assessment. available at https:// http://www.google.no/url?sa=t\&rct=j\&q=\&esrc=s\&source=web\&cd=1\&cad=rja\&uact =8\&ved=0ahUKEwiT37i464vNAhWqFZoKHUquBdsQFggbMAA\&url=http $\% 3 \mathrm{~A} \% 2$ F\%2Fwww.gfdrr.org\%2Fsites\%2Fgfdrr.org\%2Ffiles\%2Fdocuments\%2FNepal_HazardAssessment_Part1.pdf\&usg=AFQjCNGE0bQMnjaJPTz5VP6E0TCUIqMRsw\&sig2= NBs_jQgJiDdIk4UXgDZJQg\&bvm=bv.123664746,d.bGs (assessed 19 December 2016)

[3] Tianchi, L., Chalise, S.R. \& Upreti, B.N., (Eds.), Landslide hazard mitigation in the Hindu Kush-Himalayas: International Centre for Integrated Mountain Development (ICIMOD), Kathmandu, 2001.

[4] Chalise, S.R., An introduction to climate, hydrology, and landslide hazards in the hindu kush-himalayan region. Landslide Hazard and Mitigation in the Hindu KushHimalayas, International Center for Integrated Mountain Development (ICIMOD), Kathmandu, pp. 51-62, 2001

[5] Dahal, R.K., Rainfall-induced landslides in Nepal. International Journal of Japan Erosion Control Engineering, 5(1), pp. 1-8, 2012.

https://doi.org/10.13101/ijece.5.1

[6] Howell, J.H., Application of Bio-engineering in slope stabilisation: experience from Nepal. Landslide Hazard and Mitigation in the Hindu Kush-Himalayas, International Center for Integrated Mountain Development (ICIMOD), Kathmandu, pp. 147-161, 2001.

[7] Dhital, Y.P., Kayastha, R.B. \& Shi, J., Soil bioengineering application and practices in Nepal. Environmental Management, 51(2), pp. 354-364, 2013.

https://doi.org/10.1007/s00267-012-0003-7

[8] Lammeranner, W., Rauch, H.P. \& Laaha, G., Implementation and monitoring of soil bioengineering measures at a landslide in the Middle Mountains of Nepal. Plant and Soil, 278(1-2), pp. 159-170, 2005.

https://doi.org/10.1007/s11104-005-7012-8 
[9] Shrestha, A.B., Bajracharya, S.R., Kargel, J.S. \& Khanal, N.R., The Impact of Nepal's 2015 Gorkha Earthquake-Induced Geohazards. available at http://lib.icimod.org/ record/31937/files/icimod-2015-Earthquake-InducedGeohazards.pdf (assessed 17 January 2017)

[10] Rai, O.A., Back to the dark age. Nepali Times. available at http://nepalitimes.com/article/nation/earthquake-elongates-electricity-rationing,2283 (assessed 5 January 2017).

[11] Ali, N., Farshchi, I., Mu'azu, M.A. \& Rees, S.W., Soil-root interaction and effects on slope stability analysis. Electronic Journal of Geotechnical Engineering, 17, pp. 319328, 2012.

[12] Steinacher, R., Medicus, G., Fellin, W. \& Zangerl, C., The influence of deforestation on slope (in-) stability. Austrian Journal of Earth Sciences (Mitteilungen der Österreichischen Geologischen Gesellschaft), 102(2), pp. 90-99, 2009.

[13] Stewards, S., Guideline 5 - reducing erosion \& landslides, available at http://shorestewards.cw.wsu.edu/guidelines/guideline-5/ (assessed 23 Febraury 2017)

[14] DoED., Guidelines for Study of Hydropower Projects, available at http://www.doed. gov.np/documents/Guidelines-for-Study-of-Hydropower-Projects.pdf (assessed 2 February 2017)

[15] Raut, R., Risks associated with Geohazards. Master's Thesis, University of Stavanger, Stavanger, available at https://brage.bibsys.no/xmlui/handle/11250/2412528 (assessed 15 June 2016)

[16] Victoria, A., How do the properties of soils affect plant growth available at http://agriculture.vic.gov.au/agriculture/dairy/pastures-management/fertilising-dairy-pastures/ how-do-the-properties-of-soils-affect-plant-growth (assessed 10 January 2017)

[17] Gyssels, G., Poesen, J., Bochet, E. \& Li, Y., Impact of plant roots on the resistance of soils to erosion by water: a review. Progress in Physical Geography, 29(2), pp. 189217, 2005.

https://doi.org/10.1191/0309133305pp443ra 